Sociohistórica, nº 41, e050, 1er. Semestre de 2018. ISSN 1852-1606

Universidad Nacional de La Plata.

Facultad de Humanidades y Ciencias de la Educación.

Centro de Investigaciones Socio Históricas

\title{
El conocimiento antropológico en el marco del Proceso de Memoria, Verdad y Justicia. Reflexiones sobre una experiencia como "testigo de contexto" en el marco del Juicio "Operativo Independencia (primera parte)"
}

\section{Santiago Garaño *}

* CONICET - Universidad Nacional de Tres de Febrero Universidad de Buenos Aires, Argentina sgarano@hotmail.com

Cita recomendada: Garaño, S. (2018). El conocimiento antropológico en el marco del Proceso de Memoria, Verdad y Justicia. Reflexiones sobre una experiencia como "testigo de contexto" en el marco del Juicio “Operativo Independencia (primera parte)". Sociohistorica, 41, e050. https://doi.org/10.24215/18521606e050 


\section{El conocimiento antropológico en el marco del Proceso de Memoria, Verdad y Justicia. Reflexiones sobre una experiencia como "testigo de contexto" en el marco del Juicio “Operativo Independencia (primera parte)”}

Anthropological knowledge within the framework of the Memory, Truth and Justice Process. Reflections on an experience as a "context witness" in the framework of the "Operative Independence (first part)" trial

Santiago Garaño

CONICET / Universidad Nacional de Tres de Febrero /

Equipo de Antropología Política y Jurídica (ICA, FFyL, UBA), Argentina

sgarano@hotmail.com

\section{RESUMEN:}

En este trabajo me interesa reflexionar sobre una nueva figura que ha ido ganando presencia en los juicios por delitos de lesa humanidad desarrollados desde 2005: la del "testigo de contexto", aquel especialista -generalmente de las ciencias sociales- que es presentado en calidad de testigo y cuyo aporte es tomado como prueba testimonial (Abbattista, Barletta y Lenci, 2016). Para ello, me basaré en mi participación en el marco del juicio oral y púbico "Operativo Independencia (primera parte)", en el que declaré sobre mi investigación doctoral acerca de la experiencia de los soldados conscriptos en el sur tucumano durante dicho Operativo, entre 1975 y 1977. En particular, sostendré que las ciencias sociales pueden aportar reconstrucciones minuciosas de la lógica de la represión que nos ayuden a comprender cómo fue posible el ejercicio del terror de Estado.

Palabras Clave: Juicios de Lesa Humanidad, Testigo de Contexto, Operativo Independencia, Conocimiento Antropológico.

\section{Abstract:}

In this work I am interested in reflecting on a new figure that has been gaining presence in trials for crimes against humanity developed since 2005: that of the "context witness", that specialist -generally of the social sciences- who is presented as a witness and whose contribution is taken as testimonial evidence (Abbattista, Barletta \& Lenci, 2016). For this, I will rely on my participation in the oral and public trial "Operative Independence (first part)", in which I stated about my doctoral research on the experience of soldiers conscripted in the south of Tucumán during the said Operation, between 1975 and 1977. In particular, I will argue that the social sciences can provide minute reconstructions of the logic of repression that help us understand how the exercise of state terror was possible.

KeYwords: Trials for Crimes against Humanity, Context Witness, Operative Independence, Anthropological Knowledge.

\section{INTRODUCCIÓN}

En Argentina, desde el retorno de la democracia, el 10 de diciembre de 1983, la lucha incesante de los organismos de derechos humanos se ha basado en la tríada Memoria, Verdad y Justicia en relación a las masivas violaciones a los derechos humanos cometidas durante la última dictadura militar (1976-1983). En particular, han desarrollado creativas estrategias jurídicas y políticas para denunciar la implementación de un sistema nacional de desaparición forzada de personas y un plan sistemático de represión basado en el terrorismo de Estado. Gracias a esas luchas y al impulso de algunos de los gobiernos democráticos especialmente, los de Raúl Alfonsín (1983-1989) y los de Néstor y Cristina Kirchner (2003-2015)-, la experiencia argentina se ha convertido en un caso paradigmático a nivel internacional en lo que refiere a la aplicación del derecho penal y la condena de criminales de Estado, cuyo primer hito fue el histórico Juicio a las tres Juntas militares (1985). Si bien hubo interrupciones en el avance del juzgamiento de estos delitos (fundamentalmente durante la vigencia de las llamadas "leyes de impunidad" y los indultos), entre 2003 y 
2015 se selló una opción favorable hacia la persecución penal de los responsables de estos crímenes, lo que ha generado una pluralidad de experiencias concretas en este campo (Filippini, 2011).

En referencia a estas experiencias, en este trabajo me interesa reflexionar sobre una nueva figura que ha ido ganando presencia en estos juicios: la del "testigo de contexto", aquel especialista -generalmente de las ciencias sociales- que es presentado en calidad de testigo y cuyo aporte es tomado como prueba testimonial (ver Abbattista, Barletta y Lenci, 2016, p. 10) ${ }^{1}$. Para ello, me basaré en mi propia experiencia cuando fui citado a declarar en el marco del juicio oral y público que se sigue en la causa "Operativo Independencia (primera parte)", debido a la investigación que realicé para mi tesis doctoral sobre los soldados conscriptos enviados al sur tucumano durante dicho Operativo, entre 1975 y 1977.

Como he escrito este trabajo "en tiempo real", sólo podré dejar asentadas algunas preocupaciones en relación al contexto político en que se desarrolló este juicio. Desde diciembre de 2015, con la asunción como presidente de Mauricio Macri, de la alianza de derecha "Cambiemos", se observan numerosas muestras de la búsqueda de dar marcha atrás en la persecución penal de los crímenes de lesa humanidad, así como también en las políticas públicas de memoria y de reparación a las víctimas. En primer lugar, esto ocurre debido a los discursos negacionistas o los que relativizan la magnitud del terrorismo de Estado por parte de funcionarios o personalidades afines al gobierno ${ }^{2}$. Y, en segundo lugar, porque en mayo de 2017 tres miembros de la Corte Suprema de Justicia (dos de los cuales fueron nombrados luego de la asunción de Macri) fallaron a favor de aplicar una ley que permitía la conmutación de la pena de un represor. Esta medida, que fue leída socialmente como una amnistía encubierta a este tipo de criminales, sólo se pudo frenar con una masiva movilización y rechazo unánime de la mayoría de los sectores sociales y políticos.

Es en ese contexto político nuevo que, entre mayo de 2016 y septiembre de 2017, se desarrolló en la provincia de Tucumán el juicio oral y público denominado “Operativo Independencia (primera parte)", décimo segundo juicio que se inició en esa provincia por este tipo de violaciones a los derechos humanos ${ }^{3}$. Quellegase a juicio oral y público la causa por los crímenes cometidos durante el Operativo Independencia fue el fruto de numerosas luchas lideradas por el movimiento de derechos humanos de Tucumán, en particular, de Familiares de Desaparecidos de Tucumán, organización que concentró toda su energía en impulsar los procesos judiciales en esa provincia ${ }^{4}$. Pero, para que eso fuera posible, hubo que vencer numerosas resistencias para juzgar los delitos cometidos durante este operativo iniciado en febrero de 1975. Según sostuvo la Dra. Julia Vitar, la dificultad y la lentitud en el avance de la investigación sobre estos delitos se debió a que "era y continúa siendo resistido por sectores conservadores del Partido Justicialista”, debido a que la revisión implicaba avanzar sobre la responsabilidad penal de civiles - miembros de ese partido que integraron su elenco de gobierno (Vitar, 2014, p. 89)-. A su vez, si bien ya en el primer juicio "Jefatura de Policía I", el Tribunal Oral Federal se había pronunciado acerca de la existencia de un centro clandestino de detención y de crímenes de lesa humanidad en el marco del Operativo Independencia (es decir, previos al golpe de Estado de 1976), para la organización Familiares de Desaparecidos de Tucumán la elevación a juicio oral de la causa "Operativo Independencia" era una manera de negar la existencia de una "guerra" en el sur tucumano, "una de las principales representaciones del pasado cercano que el movimiento de derechos humanos buscó combatir y debatir con la realización de los procesos penales", y demostrar que en realidad se trató de un "genocidio" (Vitar, 2014, p. 109).

\section{LA CONVOCATORIA COMO “TESTIGO DE CONTEXTO"}

Hacia finales de abril del año 2016, el Ministerio Público Fiscal solicitó que se remitiera copia de mi tesis doctoral sobre la experiencia de los soldados conscriptos enviados al "teatro de operaciones" del Operativo Independencia entre 1975 y 1977, como así también de un artículo de mi autoría, con el objeto de incorporarlos como prueba en el debate oral que se llevaría adelante en la causa "Operativo Independencia 
(Primera Parte)". Una vez recibida esta notificación, recuerdo que lo primero que hice fue ponerme a disposición de la fiscalía para hacerles llegar todo el material que ellos requirieran, así como prepararme para ser convocado como testigo de contexto, como había sucedido previamente con otros colegas.

Debo confesar que lo que sentí fue una mezcla de miedo y orgullo. Miedo, porque, pese a especializarme en temas de memoria, dictadura y derechos humanos, nunca había declarado en un juicio de lesa humanidad. Orgullo, porque se me hizo patente que podía aportar parte del conocimiento que había producido en el marco de mi tesis doctoral, basada en una investigación realizada entre 2009 y 2011, entrevistando a exsoldados que habían sido enviados al teatro de operaciones del Operativo Independencia, y analizando documentos, diarios, publicaciones y revistas militares.

Desde ese momento me fui preparando para ser convocado como testigo de contexto, esa figura jurídica, entre el testigo y el perito, que se ha ido consolidando desde la reapertura de los juicios por violaciones a derechos humanos cometidas durante la última dictadura, en 2005. Recuerdo que cuando recibí el llamado del tribunal oral, esa mezcla de orgullo y miedo se transformó en un gran sentido de responsabilidad: mi tesis doctoral era uno de las pocas investigaciones que reconstruía las formas de la represión durante el Operativo Independencia. De alguna manera me reconfortó que tanto trabajo, que a veces se reduce a la presentación de textos académicos, tuviera otra audiencia: en este caso, un tribunal oral. Además, me parecía un desafío buscar incidir en un marco tan significativo: un juicio oral y público en el que se investigan los delitos de lesa humanidad cometidos con anterioridad al golpe de Estado de 1976 en una de las provincias más golpeadas por la represión ilegal, Tucumán. Es decir, que mi tesis se convirtiera en "prueba” de un juicio le daba otro sentido a ese trabajo académico: poder aportar una serie de historias y argumentos elaborados desde las ciencias sociales, para la construcción de una verdad jurídica sobre lo sucedido en Tucumán a mediados de los años '70. En ese sentido, el desafío que me planteé fue identificar los principales argumentos elaborados en la investigación doctoral.

A su vez, desde un principio consideré que no sólo era una responsabilidad académica, sino que tenía un sentido ético: poder transmitir el sufrimiento que vivieron mis entrevistados, soldados conscriptos que fueron obligados a combatir contra la llamada "subversión" en el sur tucumano. De todas maneras, cuando me avisaron que podía declarar por videoconferencia desde el Consejo de la Magistratura, ubicado en la ciudad de Buenos Aires (y no trasladarme a la ciudad de San Miguel de Tucumán), sentí cierto alivio pues la lejanía y la mediación tecnológica me permitían una cierta toma de distancia que me ayudó a despejar ciertos temores sobre el ritual judicial, que siempre tiene un halo sagrado e intimidante.

\section{El juicio “Operativo Independencia (PRimera PARTe)”}

Las audiencias de este juicio oral y público se iniciaron el jueves 5 de mayo de 2016, y se han desarrollado los días jueves y viernes en el Tribunal Oral en lo Criminal Federal de Tucumán. A partir de los diarios y portales de internet pude averiguar que la causa judicial había reunido la mayor cantidad de víctimas (271). Había 19 “imputados”, miembros del Ejército Argentino, Gendarmería y la Policía de la Provincia de Tucumán, y cerca de 1400 testigos. Por la cantidad de casos juzgados y actores intervinientes se previó una duración aproximada de más de un año, aunque finalmente se extendió hasta mediados de septiembre de 2017. Conocer el mapa de actores y las particularidades del proceso de Memoria, Verdad y Justicia en Tucumán fue clave también para identificar los principales argumentos de mi testimonio: que no hubo "guerra", sino -como sostuve en mi tesis doctoral- que en el "teatro de operaciones" del sur tucumano se había hecho una puesta en escena de una guerra que había ocultado la implementación de un sistema de desaparición forzada de personas basada en una "cultura de terror" y un "espacio de muerte" (Taussig, 2006), en fundar un "estado de excepción" (Agamben, 2004).

A la hora de preparar mi testimonio busqué realizar una operación típicamente antropológica, pero sin caer en la jerga de mi campo ni en largas digresiones disciplinares. En cambio, a partir de enseñanzas metodológicas 
que van desde Clifford Geertz (1994) a Rosana Guber (2001), busqué reconstruir la lógica del mundo de los conscriptos enviados al sur tucumano, volverla inteligible "en los propios términos" y "desde la perspectiva" de los exsoldados para que pudiera ser comprensible para el tribunal oral y el público ${ }^{5}$. En este caso, como aprendí de la mano de mis colegas del Equipo de Antropología Política y Jurídica, hacer etnografía implicaba reconstruir la lógica de la conscripción en los tiempos del Operativo Independencia, y cómo este marco de represión ilegal había alterado las prácticas, rutinas y valores que habían organizado el paso por el servicio militar obligatorio desde su creación, a principios del siglo XX. Es decir, busqué mostrar que, a diferencia de lo que había sucedido hasta ese momento, hacer la conscripción implicaba la posibilidad de matar y morir en un enfrentamiento contra un enemigo interno, y que supuso la implementación de una doctrina contrainsurgente. A su vez, luego de elucidar dicha lógica, el segundo desafío era poder traducirla y explicarla para una audiencia que no la conocía de primera mano: el tribunal compuesto por tres jueces (más el juez sustituto), pero también el nutrido público que asistía a las audiencias. En síntesis, con mi testimonio busqué realizar un típico ejercicio antropológico basado en -a partir de la fórmula de Roberto Da Matta (1999)"familiarizar lo exótico" (la experiencia de los soldados en el sur tucumano entre 1975 y 1977) y "exotizar lo familiar" (objetivar los principales ejes de mi tesis, un trabajo terminado en 2012, que desnaturaliza muchas de las representaciones que circulan socialmente sobre el servicio militar obligatorio). Sin lugar a dudas, el desafío que me impuse fue encontrar un equilibrio entre adaptar el discurso y el lenguaje para que pudiera ser comprendido por el tribunal oral, pero sin perder la legitimidad del experto, ya que había sido convocado en función de esa expertise disciplinar.

De todas maneras partía de una gran incertidumbre: no sabía qué condiciones de escucha podía tener mi testimonio como antropólogo en este "debate oral" ${ }^{6}$. Otra vez, a partir de la experiencia acumulada por el Equipo de Antropología Política y Jurídica de la Universidad de Buenos Aires, se me hizo patente que, para situarnos como actores autorizados y requeridos en el mundo judicial, antes que una mirada distante y exotizante

es la capacidad de re-narrar, de volver a representar el hecho que nos ocupa en lenguaje etnográfico, y desplegar así, la trama de relaciones no legales que le ha dado forma legal, lo que nos habilita en el oficio para que los actores -abogados, policías y activistas- nos acepten como interlocutores, capaces de explicar otra versión de la misma historia (Tiscornia, 2011, p. 2).

En ese sentido, si estaba interesado en que el tribunal comprendiera mi relato etnográfico, debía no sólo hacerlo inteligible y comprensible para los jurídico-hablantes, sino dotarlo de una densidad histórica necesaria como para conmoverlos -y convencerlos-, pero sin perder mi perspectiva disciplinar (Tiscornia, 2011, p. 6).

Con ese fin, durante una semana suspendí todas mis actividades laborales y me dediqué a releer la tesis doctoral y los trabajos que escribí sobre el tema. Debo confesar que conocer la lógica del mundo judicial y tribunalicio, gracias a mi pertenencia al Equipo de Antropología Política y Jurídica desde 2004, me dio algunas herramientas a la hora de enfrentar un juicio oral y público (sobre el que tanto he leído y estudiado). También hablé con otros cientistas sociales que habían declarado en juicios de este tipo, o que trabajan acompañando testigos. Por ejemplo, ciertos colegas me habían alertado de que, frente a cuestiones que no había abordado en mi tesis, podía responder que "no me consta", que "no recordaba", "no sé", y me habían recomendado hacer respuestas breves y contundentes. Por lo tanto, busqué los argumentos más potentes; estudié los ejes principales de mis trabajos; refiné los conceptos para que fueran comprensibles para una audiencia no académica; conversé con muchos colegas; ensayé en mi casa durante horas y horas mi planteo; y me preparé para encarar la declaración, que iba a ser una de las primeras en el marco de este juicio sobre los crímenes cometidos durante el Operativo Independencia. 


\section{LA AUDIENCIA}

El 2 de junio llegó el día de declarar en el Consejo de la Magistratura de la ciudad de Buenos Aires. Una secretaria de esa dependencia me llevó a la sala donde funciona el sistema de videoconferencias, un espacio pequeño en el que ella no sólo acompaña a los testigos, sino que certifica la validez de la declaración. Luego pude saber que antes que yo habían declarado otros testigos de contexto, y que parte de la estrategia jurídica de la fiscalía había sido iniciar este juicio con declaraciones que pudieran explicar el contexto represivo más amplio, y no centrarse en casos individuales (que iban a poblar la mayoría de las audiencias restantes).

En el televisor que tenía frente a mí la pantalla estaba partida: por un lado, la imagen del tribunal, conformado por tres miembros, en vivo y directo desde la provincia de Tucumán; por otro lado, en imágenes más pequeñas, el cuarto juez (o juez sustituto) y distintos represores acusados de delitos cometidos en el Operativo Independencia, que estaban en sus lugares de detención cumpliendo condenas por otras causas judiciales ${ }^{7}$. Ya me habían comentado que luego del interrogatorio a cargo del fiscal los militares acusados podían hacer preguntas desde los lugares de detención debido a que no tenían a su abogado con ellos. Si bien me parecía una situación muy tensionante, también estaba preparado y sabía que eso podía pasar.

Luego de saludarme y tomarme juramento, el presidente del tribunal, el Dr. Gabriel Casas, me informó que, en primer lugar, el fiscal de la causa, Dr. Pablo Camuña, me iba a realizar algunas preguntas. A continuación, el representante del Ministerio Público Fiscal me preguntó por mi formación de grado y postgrado y mi ocupación actual, seguramente con el fin de legitimar mi rol como experto en el tema sobre el que iba a declarar. Respondí que era licenciado y doctor en el área de Antropología, y agregué que defendí mi tesis doctoral sobre la experiencia de los soldados conscriptos enviados al "teatro de operaciones" del Operativo Independencia, en la Universidad de Buenos Aires en diciembre de 2012. Aclaré además que aún no había sido publicada. Luego, expuse mis credenciales académicas: "actualmente soy Investigador Asistente del CONICET; integro desde 2004 el Equipo de Antropología Política y Jurídica (UBA), y soy profesor adjunto de la Universidad Nacional de Tres de Febrero".

A partir de ese momento, durante poco más de una hora y en función de las preguntas del fiscal, intenté sintetizar los principales argumentos de mi tesis, que -destaqué- se divide en dos partes ${ }^{8}$. Expliqué que, en la parte I, titulada "Cuarteles", analizo cómo ese contexto de represión política durante el Operativo Independencia alteró la lógica de funcionamiento del servicio militar obligatorio, una institución que por esos años era casi centenaria, ya que había sido creada a principios del siglo XX en Argentina. Mientras que, en la parte II, titulada "El monte", relaté la experiencia de los soldados en el sur tucumano, a partir de febrero de 1975, cuando se inició el Operativo Independencia. Destaqué que mi tesis se centró específicamente en las puestas en escena o, en términos militares, las "tareas de acción psicológica”, es decir, las formas elaboradas por las Fuerzas Armadas argentinas para producir consenso y adhesión en torno a su accionar militar en Tucumán.

\section{El “TeAtro de operaciones” Del Operativo IndePendencia}

Luego, el fiscal me preguntó: “¿Cómo fue hacer el servicio militar obligatorio en tiempos del Operativo Independencia?". Entonces, argumenté que una de las principales preguntas de mi tesis fue "por qué, a partir de febrero de 1975, las autoridades militares construyeron al "monte tucumano" - un espacio relativamente periférico o marginal en la escena nacional- en el centro de la estrategia represiva”. Y, en ese sentido, sostuve que el Operativo Independencia tuvo dos facetas. Por un lado, una faceta que se ocultó. A partir de las palabras de Pilar Calveiro (1998) destaqué que fue en el sur tucumano el espacio en el que se implementó por primera vez de manera masiva un sistema institucional de desaparición forzada de personas, y en el que se inauguraron los primeros centros clandestinos de detención. 
A continuación, reiteré que mi tesis se centraba en los aspectos de la represión en el sur tucumano que habían sido expuestos públicamente, es decir, en las "tareas de acción psicológica”, la otra faceta del Operativo. Luego hice una digresión sobre el concepto de "teatro de operaciones" y planteé que, si bien el término forma parte de la terminología militar clásica, el uso de una metáfora o analogía dramática de la vida social (pensar el monte tucumano como teatro) me llevó a reflexionar sobre un aspecto central del poder represión: su dimensión expresiva y sus puestas en escena (Abélès, 1997).

Entonces, sostuve que el uso de ese concepto me llevó a pensar qué puestas en escena se hicieron en ese "teatro". A partir de esta línea, consideré que el sur tucumano se convirtió para el Ejército Argentino en un teatro apto para dramatizar que allí se libraba una guerra, y que para ello se valieron de unas imágenes muy caras y sentidas para el imaginario bélico y nacionalista. Destaqué que uno de los tópicos de esas tareas de "acción psicológica" fue mostrar que los protagonistas de esta supuesta guerra eran los soldados conscriptos, aquellos que cumplían el servicio militar obligatorio, como si ellos fueran los representantes de todo el pueblo argentino. Y, por otro lado, gracias al concepto de "Operativo Independencia", se buscó crear una continuidad entre este operativo y la gesta de la Independencia argentina, librada en esa misma provincia en el siglo XIX. "Ésas son dos de las puestas en escena o tópicos más potentes que se hicieron en el sur tucumano", sinteticé.

\section{LA EXPERIENCIA DE LOS SOLDADOS CONSCRIPTOS}

Sobre la experiencia de los soldados, destaqué que durante todo el año 1975 en la revista Soldado Argentino, destinada a la tropa que cumplía el servicio militar obligatorio, se buscó alentar el mandato del sacrificio de la vida, es decir, que los conscriptos estuvieran dispuestos a comprometerse activamente en la lucha que se libraba en el sur tucumano. Para ello, ilustré con los títulos de los artículos publicados en esa revista por ejemplo, "El soldado que no lucha por la patria no es un soldado" o "Por qué es obligatorio defender a la patria"- así como otros artículos en los que se realzaba el supuesto protagonismo de quienes estaban bajo bandera. Sin embargo, sostuve que los artículos reconocían que era una experiencia inédita para los conscriptos, ya que existía la posibilidad real de morir en el sur tucumano. Entonces, indiqué que no sólo se buscaba alentar este mandato, sino mostrar que era todo el Ejército, oficiales, suboficiales y soldados, que "mancomunadamente" libraba esta "batalla".

Sin embargo, argumenté que, exhibidos como "protagonistas" de esta lucha, ellos fueron en realidad espectadores del ejercicio de estas formas de represión; fueron audiencia privilegiada de estas puestas en escena que se hicieron en el sur tucumano. En este sentido, recordé que cuando los entrevisté, a diferencia de los relatos oficiales, me transmitieron que no estaban preparados para la posibilidad de morir, que les daba terror ir al monte tucumano, y que fueron obligados, es decir, que no tenían la posibilidad de negarse a esas misiones que duraban 45 días. Por ejemplo, conté el caso de uno que fue duramente castigado por negarse a ir. Expliqué que esto se debía a que básicamente no "sabían si volverían" con vida y que sentían que podía pasarles cualquier cosa. "En síntesis, creo que experimentaron en sus propios cuerpos el terrorismo de Estado, y vivieron una experiencia límite que marcó su vida y me lo han transmitido con ese dramatismo, con ese dolor, que aún me conmueve", planteé.

Cuando el fiscal me consultó si en los testimonios que integran mi tesis había casos de soldados desaparecidos durante su paso por la conscripción, expliqué que en mi trabajo de campo pude acceder a casos posteriores al período que abarca este juicio (es decir, sucedidos por fuera del primer año del Operativo Independencia). Sin embargo, destaqué que casi la totalidad de mis entrevistados me refirieron que habían sido considerados "sospechosos de ser subversivos", pese a que la mayoría no había tenido ni siquiera militancia estudiantil en sus colegios secundarios. En función de esto, destaqué cómo "en esos años, el servicio militar obligatorio era un espacio organizado por una epistemología de la sospecha y para la búsqueda de infiltrados" por parte de organizaciones armadas que operaban en nuestro país. En esa línea, narré: 
Uno me contó que lo que se consideraba más sospechoso era a quienes habían pedido prórroga y habían ingresado al servicio militar más grandes y con un paso por la universidad. Ellos eran duramente vigilados e investigados para evitar que fueran infiltrados. También, otro me contó que hacer preguntas era algo sospechoso, [por ejemplo], preguntar qué estaba sucediendo en $[\mathrm{los}]$ caso $[\mathrm{s}]$ de que veían personas torturadas. Ser tucumano y ser joven era un gran estigma. Uno me contó que le decían: “¿Vos no habrás andado con los monos [nombre que le daban a los guerrilleros] allá en el sur tucumano?”. Otro que era muy bueno en la práctica de tiro, porque había aprendido de chico, fue duramente castigado, acusado de extremista. Otro caso que, si no fuera tan terrible lo que sucedió, sería casi bizarro: como tenía el mismo apellido de un líder guerrillero [Santucho], permanentemente lo castigaron, lo hostigaron y le decían: “Usted es un guerrillero de mierda!”.

Recordé el caso de otro exsoldado que había sido secuestrado con anterioridad y que cuando ingresó al servicio militar obligatorio fue separado en un grupo de soldados "sospechados". A ellos, cuando eran enviados a hacer "operativos de rastrillaje", siempre les tocaba ir "al frente". Otro aspecto que destaqué es que muchos recordaban que los trataron "igual que a los subversivos", y sostuve que, tanto los soldados conscriptos como aquellos que eran acusados de ser activistas políticos, "ambos eran considerados sujetos cuyas vidas no valía la pena preservarlas, y por eso eran sometidos a ese tipo de maltratos”. Asimismo, sostuve que en el sur tucumano se creó un "estado de excepción”, en términos del filósofo italiano Giorgio Agamben (2004), "donde todo era posible, porque había un fuerte desprecio no sólo por la población del sur tucumano, sino también por los soldados conscriptos, lo que contrastaba con el discurso oficial de las autoridades militares”.

\section{LA DOBle FACETA DEL OPERATIVO: DeSTRUCTIVA Y PRODUCTIVA}

A continuación, el fiscal me pidió que explicara la noción de que el Operativo Independencia tenía una doble faceta: una destructiva y otra constructiva. Entonces, planteé que mi hipótesis era que el "monte tucumano" no era solamente un paisaje natural, sino que fue un espacio activamente acondicionado para estas puestas en escena. Recordé las palabras de un exsoldado entrevistado, nacido en la ciudad de Concepción y que conocía mucho la "selva tucumana", quien cuando ingresó al servicio militar obligatorio escuchó por primera vez que se hablara de esa zona como "el monte". En este sentido, a él le parecía raro referirse a esa zona como "el monte", porque para él era "la selva". A su vez, conté que él solía circular por esa zona y que luego del inicio del Operativo Independencia se volvió un "espacio del terror" (Taussig, 2006). Él, por ejemplo, solía ir a bañarse a un dique y un día cuando se dirigía allí fue divisado desde un helicóptero y casi lo matan, por sospechar que era un guerrillero. De hecho, rememoré que en su entrevista él me decía: "Yo antes andaba por la selva sin miedo y sin estar armado", y cuando ingresó al servicio militar obligatorio y estaba armado (porque era soldado), "se moría de miedo, tenía mucho temor".

Y muchos pobladores del sur tucumano, a quienes entrevisté por su condición de [ex] soldados, me comentaron que el sur tucumano se volvió un espacio muy peligroso, donde cualquiera que se atreviera a circular por ahí era un ser peligroso y sometido a la posibilidad de ser asesinado indiscriminadamente. Entonces, la represión tuvo una faceta que mostraban, y otra que ocultaban. [Y], al mismo tiempo (...) tuvo una dimensión destructiva, porque evidentemente el sur tucumano fue un espacio donde el terror atravesó todo el tejido social. Y, cuando digo eso, [quiero decir] que, como investigador nacido en Capital Federal, cuando uno habla con pobladores nacidos en el sur tucumano, la mayoría tuvo un paso por un centro clandestino de detención, que puede haber durado días, meses o más (...) En el sur tucumano, el terror atravesó todo el tejido social, y todos se volvieron seres sospechosos. Y también tuvo una faceta productiva: se produjo un espacio de excepción, donde todo era posible y se buscó alterar las relaciones sociales.

Entonces, luego de redirigirme al pedido del fiscal e indicar que aquello excedía el período de tiempo que se investiga en este juicio, retomé uno de los datos que considero "el dato más significativo" de esta faceta productiva: cómo, desde mediados de 1976, se inauguraron cuatro pueblos con nombres de supuestos "caídos" por la guerrilla, unidos por una ruta asfaltada. Esta acción, argumenté, "fue la gran estrategia final del poder militar para escenificar que se había producido un nuevo tipo de ordenamiento social, [que buscaba] disciplinar a la población del sur tucumano e imponer el dominio militar sobre ese espacio de fuerte conflicto social". 
Luego, el fiscal me preguntó si podía explicar con más detalle la noción de "construcción del concepto de guerra" y de qué manera "eso fue impregnando la faz pública y lo que se comunicaba sobre el Operativo Independencia", así como "los mitos en los que fundaron esa idea de la guerra". A partir del concepto del antropólogo Michel Taussig (2006), planteé que mi hipótesis es que en el sur tucumano se construyó reiterando otra vez el aspecto productivo- una "cultura del terror", y que para ello fue fundamental la producción de rumores y de mitos. En esta línea, señalé que "el rumor más fuerte y que más me había llamado la atención, y que yo creía que era fruto del paso del tiempo, era que la guerrilla contaba con al menos un helicóptero, desarmable, que se guardaba en bolsas, y que les permitía realizar tareas de aprovisionamiento". Pero, cuando hice trabajo de archivo con diarios de la época, pude ver que este rumor había sido creado como parte de estas "tareas de acción psicológica", "para construir a ese enemigo". Como origen de este mito, retomé una carta publicada en un diario nacional el 28 de septiembre de 1975, enviada "supuestamente desde monte", donde un oficial decía que la guerrilla tenía "al menos un helicóptero". "Esto que nos puede parecer bizarro e inverosímil fue fundamental para construir esa 'cultura del terror', porque los rumores tienen ese potencial de, al mismo tiempo que se enuncian, nos hacen experimentar acontecimientos y los producen en su propio acto de enunciación", sinteticé. Entonces, sostuve que el sur tucumano fue un espacio de fuerte producción de rumores y mitos que fueron creando una sensación de terror en la tropa: "Es decir, nadie vio al helicóptero, pero eso no impidió que no bien veían algo raro empezaran a disparar. Estaban obsesionados por ese helicóptero", recordé.

Agregué que otro de los modos de construcción de esa "cultura del terror" fue utilizar un modo muy despectivo de referirse a los acusados de opositores políticos: el concepto de "fulero" (ver Mercado, 2005). Indiqué que, para mí, que nací en Buenos Aires, el concepto de "fulero" significaba por la jerga del tango "feo, fiero". Sin embargo, cuando hice trabajo de campo en Tucumán, me di cuenta de que era el concepto que en los años 70 se usaba de modo despectivo para referirse a los militantes de izquierda, y que fue un modo de estigmatizarlos, al igual que el concepto de "mono":

De alguna manera, la construcción del enemigo se basó en este conjunto de rumores, sobre su peligrosidad, que fueron pulidos, estandarizados y producidos por el personal militar. De modo que yo veo los efectos [de esa "cultura del terror"] en el modo en que dejó una huella en los ex soldados, construyendo un clima de fuertes riesgos, construyendo a este enemigo como "fulero" y también como "mono", porque andaba en el monte, lo que nos muestra una deshumanización de aquellos que eran objeto de una persecución.

Luego, el fiscal Pablo Camuña me preguntó si en las entrevistas a exsoldados de la época se hablaba de los encuentros con la guerrilla o si tenían "grandes enfrentamientos". Entonces, respondí que me había llamado la atención cómo los entrevistados recordaban que se vivía un "simulacro de guerra", y que los supuestos "combates eran un desastre total". Respondí que me conmovió mucho un entrevistado que me contó que, en ese clima de miedo, casi se terminan matando entre compañeros, y que, antes que el relato de una "guerra", mis interlocutores me hablaban de haber vivido el terror en carne propia.

Luego, me pidió que hablara del concepto de la “espectacularización del terror”. En ese sentido, expliqué que tiene que ver

con un terror que al mismo tiempo que se oculta, en los centros clandestinos de detención, [también] se muestra, o se escenifica, en el control poblacional, en los fuertes operativos de detención, en la aparición de cuerpos tanto en la vía pública, o tirados en el monte. Todo eso se mostraba.

A su vez, agregué que la espectacularización de la violencia tenía una "función moralizante". Recordé un caso que muchos entrevistados me contaron, y que considero como un lugar común de esas memorias: el de aquel sordo que iba caminando y, como por razones obvias no escuchó la "voz de alto" en un puesto de control militar, fue asesinado. Afirmé que no podía dar detalles acerca de cuándo sucedió, ni dónde, ni quién fue la víctima, pero sostuve que esas víctimas casuales, que no eran opositores políticos, también fueron víctimas del 
terrorismo de Estado. Y destaqué que tenían una función de multiplicar el terror, porque creaban la noción de que toda persona que estaba en el sur tucumano era susceptible de ser asesinada.

Ahí es donde el terror funciona no como mero estado psicológico, sino como una construcción social para imponer el miedo en la población. Y esta figura de la víctima causal -como lo fueron muchos pobladores del sur tucumano- eran la prueba irrefutable de la arbitrariedad de la represión y de que todos estaban sometidos a ese "poder desaparecedor" [Calveiro, 1998], a ese poder del terrorismo de Estado.

Y concluí con el planteo de que esto se debía a que se había creado un "estado de excepción” en el sur tucumano -según el concepto de Giorgio Agamben (2004) - “donde todo era posible y no había garantías constitucionales.

\section{LA ACCIÓN DE PROPAGANDA}

El fiscal me pidió que explicara cómo se construyó la "significación pública" sobre el Operativo, es decir, qué tipo de "acciones de propaganda y qué medios utilizaban" para construir un "mensaje" que le daba "un sentido a lo que estaba pasando en el sur tucumano". Para ello, destaqué que las puestas en escena del poder militar tuvieron distintas audiencias. Por un lado, los soldados y la población del sur tucumano, que vieron en carne propia esa violencia, y, por otro lado, también se produjeron mensajes cuya audiencia principal fue la sociedad argentina.

Sobre este último punto, destaqué que, entre estas puestas en escena, se destacan las visitas de periodistas que fueron enviados a la zona de operaciones en noviembre de 1975. Sostuve que fue "un gran operativo de propaganda”, a partir del cual se buscó construir un relato sobre lo que estaba sucediendo:

Obviamente no se mostraba lo que sucedía en los centros clandestinos de detención; se mostraba esa especie de escenario bélico. Si ustedes ven la cobertura de los medios, hay un relato muy pulido, muy estandarizado; se construye el 'monte' como un espacio muy peligroso, de naturaleza salvaje, lleno de secretos y peligros.

Para ilustrar esta afirmación, pedí permiso para leer un fragmento de un artículo publicado por la revista Gente, en el que se reseñaba la visita de los periodistas a la "zona de operaciones" del Operativo Independencia, con un tono propagandístico:

Un oficial me explica cómo es esta guerra: "Por lo general un contacto, es decir divisar al oponente, dura con mucha suerte diez a quince minutos. A partir de ahí todo es cuestión de suerte. El monte es un infierno. Si el oponente va por una senda y es divisado, inmediatamente entra en el monte. Allí es casi imposible ver más allá de las propias narices. Uno camina y no sabe si al lado hay un hombre apuntándole. Aquí la vida está en juego a cada rato. Incluso ahora no sabemos si puede haber alguien apuntándonos". Instintivamente miro a mi alrededor. El oficial se ríe y me dice: "No se preocupe que usted tampoco va a verlos..." 9 .

Indiqué que esta frase me parecía "muy significativa” porque mostraba las estrategias a partir de las cuales se construyeron dos tópicos sobre esa lucha que se estaba librando: la del "monte" como un lugar de mucho peligro, y también la de un enemigo muy peligroso, aunque bastante difuso. "Fíjense que dice "no se preocupe que no va a ver a nadie'. Lo cual es casi una 'confesión de parte' de que ya no había nadie ahí... Pero eso ya es una conjetura [mía]".

Agregué que estos tópicos fueron muy importantes para construir esa "cultura del terror" y para difundirla no solo entre los pobladores y en la sociedad argentina, sino en la propia tropa: "que estuvieran aterrorizados y que también estuvieran dispuestos a hacer cualquier cosa en ese contexto del terror”. Asimismo, recordé que también se exaltó la figura de los soldados como protagonistas de la lucha.

Pero todos esos tópicos [fueron] muy pulidos, porque uno puede ver en los distintos medios de comunicación, el mismo relato, que se repite el mismo relato, que ya está muy estandarizado, y que es muy distinto a las coberturas mediáticas del año 1974 . 
Por último, destaqué cómo se hizo una "gran puesta en escena" en ese "teatro" que era mostrable; se construyó la idea de un lugar muy adverso; de que los protagonistas eran los soldados conscriptos; de que había un enemigo muy peligroso; pero, fundamentalmente, de que ahí se libraba una "batalla central" contra la guerrilla.

Cuando el fiscal me preguntó cuál era la razón de eso y si pude encontrar algún documento donde estuviera delineada "una estrategia de comunicación y propaganda" por parte del Ejército o de las FFAA, le respondí que yo me limité a reconstruir las acciones de propaganda e identifiqué un "patrón o lógica" en esas tareas de acción psicológica. De todas maneras, aclaré que no accedí a los planes militares y que entendía que había otros investigadores que habían trabajado con documentación militar.

Luego, retomé la pregunta de "por qué Tucumán”. Para responder esa pregunta sumé un elemento que, a primera vista, parecería contradecir la centralidad que tenía el monte tucumano en la estrategia de las Fuerzas Armadas. Detallé que el primer comandante de la V Brigada de Infantería Acdel Vilas escribió un manuscrito sobre su experiencia en el sur tucumano ${ }^{10}$. En este libro reconocía que la ciudad de San Miguel de Tucumán -y no el monte- era el "verdadero meollo del problema". Pedí permiso para leer un extracto de su libro:

¿Por qué los nombrados grupos operativos desenvolvían su acción en el ámbito de la capital, principalmente? Pues porque de las declaraciones tomadas en [el centro clandestino que funcionaba en] Famaillá llegamos a la conclusión de que la base de operaciones del ERP era la ciudad y no el monte como suponían algunos. Sin la cobertura que les daba Tucumán, los campamentos situados en plena selva no hubiesen resistido treinta días de lucha, pero el foco de la infección marxista estaba en San Miguel y resultaba un esfuerzo baldío creer lo contrario. De aquí que mi determinación de incluir en la zona de operaciones a la capital haya sido correcta (Vilas, 1977).

Entonces, volví a preguntar por qué el sur tucumano había sido construido como “centro" si el mismo Vilas había reconocido que el "centro de agitación política" estaba en la ciudad. Para ello, retomé el argumento central de mi tesis: que eso se debía a que ahí se pudo hacer una puesta en escena de una "guerra", a partir de la apelación a valores nacionalistas muy potentes, que obviamente buscaban generar la adhesión social en relación a ese operativo represivo. Pero, sobre todo, porque en ese "teatro" se podían montar escenas de la represión que se podían mostrar a la sociedad argentina (es decir, que eran mostrables), mientras que no se podía mostrar el horror que sucedía en los centros clandestinos de detención. Y sostuve que, por la apelación a estas imágenes nacionalistas, el sur tucumano se volvió una escenografía muy propicia porque, "aunque suene paradójico, mostrando lo que sucedía en el sur tucumano [se podía] ocultar lo que sucedía en los centros clandestinos".

A continuación, el fiscal me preguntó qué significaban las visitas de autoridades nacionales al sur tucumano. Sostuve que durante 1975 las más importantes fueron las visitas de periodistas y que, durante el año 1976 (que no es periodo que aborda el juicio), también fueron a conocer la zona, ministros, deportistas, autoridades de la Iglesia, artistas, porque el "monte tucumano" era un espacio mostrable donde se podía hacer una puesta en escena de una "guerra”. En relación a la presidenta constitucional, María Estela Martínez de Perón, recordé que ella fue a las localidades de Famaillá y Santa Lucía, acompañada del ministro de Defensa y el de Bienestar Social, unas pocas horas en abril de 1975, con el fin de demostrar que ellos supervisaban lo actuado por las Fuerzas Armadas. Sin embargo, señalé que la funcionalidad de estas visitas que se acentúan en 1976 era construir a Tucumán como el "centro" de lo que estaba sucediendo a nivel represivo.

\section{Los ASPECTOS METODOLógicos}

Por último, el fiscal me consultó sobre la cantidad de entrevistas que había realizado, y le contesté que mi trabajo de campo se compuso de 19 entrevistas a exsoldados de las clases 52 a 59 y la consulta de mucho material documental: relevé el diario La Gaceta entre 1974 y 1977, revistas militares (como Soldado 
Argentino, Revista del Suboficial, Revista del Círculo Militar y la Revista de Educación del Ejército), artículos periodísticos de revistas y diarios nacionales, y libros testimoniales.

\section{LAS PREguntas DE ABOgados QUERELLANTES, DEFENSORES E IMPUTADOS}

Una vez respondidas todas las preguntas de la Fiscalía, el presidente del tribunal habilitó a los abogados querellantes a hacer preguntas, quienes en principio no realizaron ninguna. El Dr. Edgardo Adolfo Bertini, uno de los tres miembros de la "defensa pública", fue el primero que tomó la palabra:

Defensor Público: Buen día, quiero hacerle dos preguntas en relación a su tesis. Usted acaba de decir que entrevistó a 19 exconscriptos, ¿es así?

Testigo de contexto: Efectivamente.

Defensor Público: De las clases 52, ¿a cuánto?

Testigo de contexto: A la Clase 59.

Defensor Público: ¿Usted sabe qué porcentaje representan esos 19 sobre el total de conscriptos que hubo en esa época?

Testigo de contexto: En principio, le agradezco la pregunta. Al teatro de operaciones eran enviados en misiones de 45 días, soldados provenientes de todas partes del país, pero sobre todo de la V Brigada de Infantería. Por las entrevistas pude ver que la mayoría eran de Tucumán, Salta y Jujuy, pero también de otros lugares. Yo no sé exactamente la cantidad, pero sí le puedo decir que muchos de mis entrevistados me refirieron que en esos años aumentó la cantidad de soldados convocados, incluso fueron convocados soldados con algún tipo de problema físico o con baja estatura, supuestamente, por el "problema de la guerrilla”.

Defensor Público: O sea que sobre el total común, habría habido más... Le hago otra pregunta...

Testigo de contexto: Yo entrevisté a todos lo que pude acceder...

Defensor Público: Otra pregunta. En este trabajo de campo, qué hizo usted, ¿entrevistó a miembros de Fuerzas de Seguridad o Armadas que hayan estado vinculados con delitos de lesa humanidad, que...?

Testigo de contexto: Yo intenté hablar con miembros de las Fuerzas Armadas, pero ellos no quisieron hablar conmigo.

Defensor Público: Pero eso, ¿no figura en su tesis? No figura, ¿̨no?

Testigo de contexto: Por eso mi tesis se centra en los soldados conscriptos, es decir, aquellos que fueron obligados porque cumplían el servicio militar obligatorio...

Defensor Público: Pero disculpe que lo interrumpa. Esta negativa por parte [de los miembros de las Fuerzas Armadas], no está asentada en la tesis. Porque yo la vi, pero no tuve la posibilidad de encontrar esta negativa... ¿Es así?

Testigo de contexto: Está por la positiva. Está lo que pude hacer, no lo que no pude...

Defensor Público: Gracias, doctor, que tenga buen día.

Luego el Dr. Facundo Maggio, por la defensa particular de uno de los imputados, me preguntó:

Defensor particular Maggio: Buenos días. A raíz de su estudio y profunda investigación, le quiero hacer unas preguntas. Usted al principio de su exposición dijo tener cierto conocimiento o estudio de cuestiones militares, de reglamentos militares, ¿es así? Porque la pregunta viene después de eso... La fiscalía dice que no [responda], pero prefiero que me conteste...

Testigo de contexto: No, dije que no.

Defensor particular Maggio: ¿Conoce sobre Código de Justicia Militar?

Testigo de contexto: No.

Defensor particular Maggio: Cuando usted hace referencia al "teatro de operaciones", ¿hace referencia a la zona de operaciones establecida en la zona de Tucumán? ¿A qué hace referencia específicamente?

Testigo de contexto: Yo expliqué que, si bien es un término que proviene de la terminología militar, a mí el concepto de "teatro de operaciones" me inspiró a una reflexión sociológica e histórica sobre cómo era ese espacio llamado "teatro de operaciones" (...) me llevó a pensar qué puestas en escena se habían hecho en ese "teatro". Es un uso, si se quiere, metafórico de un concepto bélico, es con fines de iluminar una dimensión que puede ser la "acción psicológica” y que yo llamo "puestas en escena"...

Defensor particular Maggio: Si, sí, eso me quedó claro... Otra pregunta. Usted dijo que una especie de estrategia final era poner nombres en el sur tucumano de cuatro personas que habrían muerto por la guerrilla. Yo le pregunto si usted conoce los nombres de esas poblaciones y los hechos que dieron lugar a poner esos nombres, las circunstancias que llevaron a poner esos nombres, de las personas... 
Testigo de contexto: Entiendo que no se refiere al periodo de estudio. Sí, fueron cuatro poblaciones unidas por una ruta, que lo que yo analizo en la tesis es cómo fueron utilizadas como una puesta en escena por el personal militar para ratificar un dominio sobre esa zona conflictiva.

Defensor particular Maggio: Está claro... (... ) Sí, pero como usted refiere a cuestiones de contexto, le pregunto si nos puede decir el nombre de esas poblaciones, y si sabe qué pasó con esas personas en la historia o el período éste donde habrían sido "abatidas"...

Testigo de contexto: Teniente Berdina, Capitán Cáceres, Soldado Maldonado y ahora tendría que revisar el último...

Defensor particular Maggio: Y, ¿qué habría pasado con esas personas? Usted dijo que habrían sido abatidas por la guerrilla si no entendí mal.

Testigo de contexto: Yo lo que digo es otra cosa. Yo lo que quiero decir es que sus vidas, y le agradezco mucho su pregunta, porque quiero enfatizar [esta idea] y no pude hacerlo en mi exposición. Yo lo que digo es que esas vidas fueron construidas en términos de "víctimas". Que más allá de los hechos, sobre los cuales yo no investigué particularmente...

Defensor particular Maggio: Ah, ésa era la pregunta...

Testigo de contexto: Fueron construidas como figuras paradigmáticas que se habían "sacrificado en aras de la victoria", etc, etc, etc...

Defensor particular Maggio: Pero, ¿¿Usted no investigó sobre esos hechos?

Testigo de contexto: Entonces estas figuras fueron construidas por el personal militar y tuvieron una función central en esto que yo llamo buscar la legitimidad...

Defensor particular Maggio: Disculpe, pero no está contestando la pregunta, ¿no sabe si fueron fantasía o realidad esos hechos que habrían dado origen a esos pueblos...?

Testigo de contexto: No, no los investigué [eso], yo investigue...

Defensor particular Maggio: Usted recuerda que habrían visitado la zona sur tucumana, estudiantes, miembros de la Iglesia, ministros. Sobre los ministros, usted sabe, porque usted comentó, ¿sabe declaraciones de ministros de esa época relacionadas con la situación que se vivía en el país entre los años 1974 y 1977 ? Y le pregunto por ministros y personalidades por si recuerda alguno: [Y cita una serie de nombres y fechas, en muchos casos con extrema rapidez]. ¿Conoce alguna declaración relacionada con esa situación conflictiva en el país?

Testigo de contexto: Yo no trabajé con declaraciones del año 1974.

Defensor particular Maggio: Disculpe, por eso era la pregunta...

Usted dijo que no conocía los reglamentos ni el código de justicia militar. Sin perjuicio de eso, ¿̇usted conoce las sanciones que podían existir a oficiales que desobedezcan una orden en un enfrentamiento?

Testigo de contexto: Le estoy diciendo que yo trabajé con soldados conscriptos, no con oficiales...

Defensor particular Maggio: Por ahí le contaron... por eso le pregunto... ¿No sabe? No, no importa... Con respecto a la presidenta Estela Martínez de Perón, usted hizo referencia a ella. ¿Qué opina usted, o si hizo algún estudio primero respecto a lo que dio lugar a determinadas acciones en Tucumán? Y, si sabe si en esas pocas horas qué tipo de declaración hizo en el sur tucumano, frente a personas o autoridades del pueblo. ¿Conoce?

Testigo de contexto: Sí, claro. Hizo muchas declaraciones. Sé que estuvo en Santa Lucia y también estuvo en Famaillá, donde se dirigió al público. Las declaraciones forman parte de mi tesis que, si me lo permiten, me gustaría remitir una copia a tribunal.

Defensor particular Maggio: Concretamente y pregunto por las declaraciones que hizo en esas pocas horas. Si tiene esa transcripción....No tengo problema que la aporte al tribunal, pero le pido que la lea...

Fiscal: Sr. Presidente, está ofrecida la copia completa que incluye esa declaración...

Presidente del Tribunal: Está ofrecido el libro, así que es superabundante. ¿Dr. Leiva?

Coronel Lazarte: Desde Marcos Paz, el coronel Lazarte quisiera hacer uso de la palabra -desde la videoconferencia...

Presidente del tribunal: Un segundito, coronel Lazarte. Primero va a hacer preguntas el Dr. [Mario] Leiva aquí...

Abogado Defensor Leiva: Buen día, licenciado, dos cositas. Usted manifestaba que los soldados fueron testigos de ese espectáculo y que tenían medio de morir en el monte... En función de las charlas que usted tuvo con estos soldados, ¿alguno de ellos le informó contra quién era [la guerra], quién era el enemigo, o contra quién supuestamente peleaban...?

Testigo de contexto: Y, mire, depende mucho de... Un entrevistado me contó que le tocó pasar navidad en el sur tucumano, lleno de miedo, y se preguntaba: ¿Qué estoy haciendo acá, qué estoy haciendo acá? Lo que a veces le decían cuando los llevaban al sur tucumano, era que iban a un concurso de tiro. Si bien les hablaban mucho de la lucha, y todas las arengas para construir ese tipo de terror, muchos de ellos me manifestaron ese desconcierto sobre qué hacían ahí...

Defensor Leiva: De los 19 testigos, digo, soldados que usted entrevistó, sobre un total de 623 [no se entiende el número], ninguno de los 19 le ha manifestado a quién ha enfrentado...

Testigo de contexto: Se entrecorta...

Defensor Leiva: Le reitero. Si de los 19 ninguno le pudo manifestar de forma concreta, a quiénes enfrentaron...

Testigo de contexto: Mire, usted sabe que un detalle que me llamó la atención es que me preguntaban a mí cuántos eran: “¿Usted sabe cuántos eran? Porque a nosotros nos decían que eran 5 mil... ¿Vos sabes cuantos eran?”. Yo, como no me centré 
en la experiencia de la guerrilla, no les podía decir cuántos eran; pero sí fue fuerte el mito que construyeron que en el sur tucumano se libraba una guerra y que hubo miles y miles de guerrilleros, y esto sigue siendo una incógnita: “¿Cuántos eran...?”.

Defensor Leiva: Yo no le pregunto cuántos eran... ya le pregunté de dos formas distintas y no contesta... No me interesa saber cuántos eran... Cuando usted hace referencia a las tareas de acción psicológica, los militares han creado un teatro para hacer creer que en el sur tucumano se libraba una guerra. ¿A qué hace referencia con esa frase?

Fiscalía: Contestó ya dos veces la misma pregunta...

Presidente del tribunal: Las consideraciones sobre la respuesta corren por cuenta suya; él le da su opinión con respecto a lo que él consideraba que un soldado [pensaba] con respecto al enemigo, digamos...

Defensor Leiva: Perdón que lo aclare, son dos preguntas totalmente diferentes... Primero yo pregunte si habían luchado y contra quién. Porque no lo sabe....

Presidente del tribunal: Perdóneme, yo creo que ya está claro lo que él piensa, sobre que fue un teatro de operaciones, que fue una representación. No significa que sea la verdad absoluta...

Defensor Leiva: Seguramente que no creo bajo ningún punto de vista que...

Presidente del tribunal: Las consideraciones no tienen por qué ser satisfactorias a sus inquietudes...

Defensor Leiva: Yo le estoy preguntando otra cosa. La primera no me responde... La primera. Y la segunda, que se libraba una guerra... Yo le pregunto a él concretamente qué significa eso que los militares han, que no lo sabe que significa que crearon un teatro, para hacer creer que en el sur tucumano se libraba una guerra...

Presidente del tribunal: La pregunta es, ¿por qué él dice que hicieron creer que se libraba una guerra?

Defensor Leiva: Ahí está, mejor...

Testigo de contexto: Yo creo que ya lo respondí. Le agradezco la aclaración. Lo que yo planteo es que se hizo una puesta en escena que fue muy funcional en torno a las tareas represivas... Y que para ello se valieron de imágenes muy sentidas para el imaginario bélico y nacionalista. ¿Qué más sentido [o significativo] que un soldado conscripto? O, ¿qué más sentido que Tucumán, una provincia donde se libraron batallas fundamentales, por la primera Independencia, por la Independencia? Creo que los militares jugaron con ese imaginario...

Presidente del tribunal: Muy bien. Ahora le va a formular preguntas uno de los imputados, desde su lugar detención, el Sr. Lazarte... ¿Sr. Lazarte?

Coronel Lazarte: Sí, habla el coronel Lazarte. Dr., por lo que pude escuchar es un proyecto de tesis o una tesis doctoral, que sustenta el testigo. En principio, parece ser que desconoce cuál es la génesis de lo que se estaba librando...

Fiscalía: Son apreciaciones...

Presidente del tribunal: Bueno, eso ya son consideraciones suyas... Lo que usted quiera preguntarle, Sr. Lazarte... Él ha hecho una tesis doctoral, bien o mal según su criterio, pero que ha sido aprobada y felicitada por el tribual evaluador. Usted pregunte lo que pueda serle de su inquietud al testigo...

Imputado: Yo la calificaría de paupérrima, pero de todas maneras, la pregunta es: ¿̇sabe el testigo cuál es la génesis de la guerra que se libró en la provincia de Tucumán y cómo se llegó a esa guerra?

Presidente del tribunal: No, no, es un especialista... ¿Ha entendido la pregunta?

Testigo de contexto: Sí, mire yo quiero hacer una aclaración sobre las reglas que atienen a mi disciplina. Yo soy un investigador, especialista en historia reciente. Para poder hacer esta tesis conté con dos becas del CONICET, que es el Consejo Nacional de Investigaciones Científicas y Técnicas, que son becas que se obtienen mediante un concurso nacional, muy selectivo, y esa tesis fue aprobada. Con base a esa tesis publiqué artículos, que también fueron sometidos a doble referato. Entonces (...) mis hipótesis son discutibles, en sentido de que se puede estar de acuerdo o no, pero el campo de la investigación tiene reglas de producción de conocimiento. Lo que yo digo ha sido sometido a múltiples instancias de evaluación, tanto por quienes han evaluado mi tesis como las becas, (...) como en los artículos. En relación a la pregunta, lo que yo le puedo responder es que el Operativo se inició en cumplimiento de un decreto; que ya había habido operativos previos en el año 74 , que habían estado a cargo sobre todo de la Policía Federal, y en el 75, el 9 de febrero, se inicia por un decreto presidencial...

Lazarte: No responde a lo que yo pregunto...

Presidente del tribunal: Bueno, ésa es su evaluación... ¿Alguna pregunta? De todas maneras, una génesis formal dio....

Lazarte: Lo que coloca es el origen, la matriz del problema que se iba a... porque de lo contrario, estamos haciendo un relato que ya ha aparecido en 5 mil libros que relatan lo que ha sucedido en ese nefasto período de la guerra revolucionaria en Argentina. Esto es lo que quería decir...

Luego vino el tiempo de los requerimientos del cuarto juez, o juez sustituto, que me preguntó si, además de diarios y revistas de la época, había consultado la revista Estrella Roja "que era el órgano del Ejército Revolucionario del Pueblo”, a lo que contesté que sí, en el Centro de Documentación e Investigación de la Cultura de Izquierda (CEDINCI).

Por último, uno de los abogados querellantes de la Asociación por la Memoria, la Verdad y la Justicia de Santiago del Estero me consultó si en el marco de mis investigaciones había podido indagar sobre la llamada 
“teoría de los dos demonios", la que equipara los crímenes de la guerrilla con los del Ejército, “como una teoría para justificar los crímenes que estamos investigando". Frente a ese requerimiento, respondí que, si bien era una "continuidad de la teoría de la guerra", prefería no responder porque hay especialistas que trabajaron sobre la génesis de esa teoría. Luego de ello, el presidente del tribunal me dijo: "Ahora sí, está desocupado, puede retirarse, vamos a hacer un cuarto intermedio...”.

\section{PARA CERrar}

Sin lugar a dudas, el cierre de mi declaración como "testigo de contexto" estuvo marcado por la tensión que viví debido a la hostilidad de las preguntas de los abogados defensores y de uno de los imputados, de quien luego supe que había tenido un rol central en el aparato de inteligencia montado durante el Operativo Independencia. En este sentido, de mi experiencia en este juicio oral, lo que me quedó claro fue el rechazo que despertó en la Defensa de los acusados, el concepto de que en el sur tucumano se había montado un "teatro", basado en una serie de puestas en escena del poder militar. Esto muestra cómo en estos juicios se dirimen no sólo la verdad jurídica, sino también la búsqueda de imponer un relato legítimo sobre la historia reciente, una memoria pública que pueda llegar a ser socialmente aceptada. En este sentido, mi declaración fue considerada muy perturbadora para aquellos que sostienen que en el sur de Tucumán se libró una "guerra". De hecho, colegas que presenciaron mi declaración en la sala de audiencias me comentaron cómo el público que acompañaba a los acusados se indignó con mi declaración como testigo de contexto.

Para cerrar, quiero dejar instalada una pregunta, sobre la que no tengo una respuesta definitiva: ¿para qué puede servir este tipo de declaraciones realizadas en un juicio por delitos de lesa humanidad? De más está decir que, además del nuevo contexto político a nivel nacional, no sé qué efectos jurídicos tendrá mi participación como testigo de contexto. En particular, debido a que en este tipo de procesos penales los principales elementos de prueba jurídica de los hechos investigados son los "testigos-víctimas", es decir, aquellas personas que dan testimonio sobre delitos de lesa humanidad, y a su vez ellos mismos fueron víctimas de violaciones a los derechos humanos (Vitar, 2014, n. 92). En este sentido, en la mayoría de estos juicios son los sobrevivientes del horror la principal prueba disponible sobre los hechos investigados, dada la destrucción u ocultamiento del material documental sobre el accionar ilegal, secreto y clandestino del aparato represivo del terrorismo de Estado (ver Varsky, 2011).

De todas maneras, en principio, quiero destacar que en lo personal declarar en el Juicio del Operativo Independencia tuvo una dimensión que puedo llamar "reparadora". Me explico: desde el año 2008 que tengo dedicación exclusiva a la investigación y docencia universitaria, a escribir y a pensar, siempre con apoyo del Consejo de Investigaciones Científicas y Tecnológicas (CONICET) y de universidades públicas. Luego de declarar en este juicio, sentí que haber trabajado tantos años en una tesis doctoral ahora tenía "otro sentido", otro valor, otro impacto, y otros usos inesperados, que me reconfortaron y me vuelven a reconectar con la importancia de la tarea emprendida.

En este sentido, considero que las ciencias sociales pueden aportar una nueva manera de mirar la represión estatal, así como sumar argumentos en pos de uno de los ámbitos hegemónicos para la construcción de una verdad sobre lo sucedido en el pasado reciente dictatorial argentino: la justicia penal, espacio en el que se juzgan estos crímenes de Estado. Para ello, quiero señalar tres recaudos.

En primer lugar, si desde el Equipo de Antropología Política y Jurídica algo hemos aprendido a lo largo de estos años de investigación entre abogados y funcionarios judiciales es que el lenguaje jurídico ejerce una suerte de fascinación sobre los antropólogos que trabajamos en ese mundo (Sarrabayrouse Oliveira, 2009). Esto hace que en muchas ocasiones comencemos a "hablar en jurídico" (Tiscornia, 2011), olvidando que parte de nuestra tarea es poder distanciarnos de ese lenguaje - una vez que hemos logrado acercarnos- para poder explicar qué suponen y significan todas esas categorías (Sarrabayrouse Oliveira, 2009). Desde esta perspectiva, consideramos que nuestra finalidad no es convertirnos en meros traductores de expedientes 
judiciales, sino poder reconstruir prácticas, lógicas burocráticas y relaciones entre grupos, fenómenos éstos que se encuentran velados tras ese abigarrado lenguaje y esas formas excesivamente reglamentadas que caracterizan al mundo judicial (Sarrayrouse Oliveira, 2009).

En segundo lugar, ser convocado en calidad de "testigo de contexto" tampoco implica hacer gala de discusiones meramente disciplinares como antropólogos. Ello es así porque (sin dejar el lugar de experto) debemos ajustar nuestro lenguaje de acuerdo a los contextos -en este caso, un juicio oral- y, pensando en la audiencia sobre la que se busca incidir -el tribunal-, incorporar algunos términos que ayuden a establecer un diálogo fértil con el mundo jurídico. Durante la experiencia analizada, como no sabía si el saber antropológico estaba legitimado en el tribunal oral tucumano, ni si los actores estaban dispuestos a incorporar esa perspectiva, traté de no retomar mis planteos más antropológicos ni utilizar conceptos típicamente antropológicos como el de reciprocidad, sacrificio, y ritual (que sí usé en mi tesis doctoral).

En tercer lugar, en las causas judiciales contamos con un material documental y testimonial valioso para reconstruir ese pasado. Si bien muchos colegas de las ciencias sociales ya hemos consultado esta documentación (en calidad de investigadores, peritos o incluso como integrantes del Poder Judicial), por momentos siento que una mera "lectura jurídica" no alcanza para extraer todo el rico material que estas causas tienen a la hora de interpretar el pasado reciente. Por lo tanto, creo haber mostrado que desde las ciencias sociales se puede ampliar el registro de preguntas y complejizar la reconstrucción de un pasado sobre el que aún falta tanto reconstruir, sobre todo si salimos de las discusiones meramente jurídicas sobre cómo tipificar los delitos cometidos (¿caben o no los crímenes en el concepto de genocidio?) (ver Feierestein, 2012). En cambio, considero que podemos colaborar en la reflexión sobre las condiciones de surgimiento, así como en las reflexiones sobre las tramas sociales sobre las que se sustentó el terrorismo de Estado.

En síntesis y para cerrar, considero que nuestro aporte es buscar un lenguaje propio y distintivo para las ciencias sociales, en tanto que no tenemos que hablar en "jurídico" o "en jerga militante" de los derechos humanos para ser comprendidos por esos mundos. Es decir, que podemos ser escuchados si hablamos desde nuestro propio lugar de enunciación, como científicos sociales, y hacemos lo mejor que podemos hacer: reconstrucciones minuciosas que dan cuenta de problemas sociales y complejizan discusiones que nos ayudan a entender cómo fue posible el ejercicio de formas tan extrema de represión estatal. Es decir, creo que el desafío es seguir escribiendo etnografías de ese pasado reciente, que nos permitan desentrañar la lógica de la represión política para denunciarla e impugnarla. Y, sobre todo, que ese relato tenga la densidad necesaria para conmover y convencer no sólo a los jueces sino a la sociedad tucumana y argentina.

\section{Post SCRIPTUM}

Luego de 16 meses de debate oral, 88 audiencias, la declaración de 455 testigos y ocho inspecciones oculares a distintos espacios vinculados al terrorismo de Estado, el 15 de septiembre de 2017, el Tribunal Oral Federal de Tucumán dio a conocer la sentencia en este juicio histórico. En ella, se condenó a cadena perpetua por delitos de lesa humanidad a Roberto "El Tuerto" Albornoz, Ricardo Oscar Sánchez, Miguel Ángel Moreno, Enrique José del Pino, Luis Armando De Cándido y Jorge Omar Lazarte; se impusieron penas de entre 18 y 4 años a cuatro acusados (Néstor Castelli, 18 años de cárcel; Jorge Gerónimo Capitán, 16 años; Manuel Rubén Vila, 10 años; y a Pedro Alfonso López, cuatro años), mientras que 7 fueron absueltos (José Ernesto Cuestas, Ramón César Jodar, Francisco Camilo Orce, José Luis Del Valle Figueroa, Alfredo Alberto Svendsen, José Roberto Abba y Omar Edgardo Parada) ${ }^{11}$. Frente a este veredicto, mientras los organismos de derechos humanos de Tucumán celebraron el logro de que se hubiera reconocido que durante el Operativo Independencia se habían cometido delitos de lesa humanidad, también cuestionaron las penas en algunos de los imputados con notables responsabilidades en el aparato represivo, el uso de ciertas figuras jurídicas (como el "error de prohibición”) y las absoluciones de los imputados. A su vez, concluyeron que "las características 
de la sentencia de la causa Operativo Independencia nos obligan a seguir exigiendo y luchando por justicia. Sabemos que lo imposible sólo tarda un poco más, y lucharemos para conseguirlo" ${ }^{12}$.

Sin lugar a dudas, la lectura y el análisis de las más de 1000 páginas de los fundamentos de la sentencia, que se dieron a conocer el miércoles 8 de noviembre de 2017, tomará mucho tiempo de conversaciones y debate con operadores del campo jurídico y activistas del mundo de los derechos humanos. De todas maneras, este juicio abrió en mí una nueva serie de preguntas de investigación -de manera general- porque vislumbré la importancia de seguir dedicándome a la reconstrucción etnográfica e histórica del terrorismo de Estado en Tucumán, desde una mirada microhistórica. Y, particularmente, porque en el caso del Operativo Independencia considero que aún resta hacer una cartografía de las formas de represión social y política desplegadas en el sur tucumano. A ello me abocaré los próximos años.

\section{REFERENCIAS}

Abbattista, L., Barletta, A., y Lenci, L. (En prensa). La Historia va al Tribunal en La Plata. Una vuelta de tuerca sobre Comprender y Juzgar. En J. Piovani y N. Werz (Coord.), Desafios de la construcción de un campo problemático conjunto en memorias, transiciones e identidades. Berlín: Instituto Iberoamericano de Berlín.

Abélès, M. (1997). La antropología política: nuevos objetivos, nuevos objetos. Revista Internacional de Ciencias Sociales, $153,15$.

Agamben, G. (2004). Estado de excepción. Buenos Aires: Adriana Hidalgo Editora.

Águila, G. (2010). Los historiadores, la investigación sobre el pasado reciente y la justicia. En J. Cernadas y D. Lvovich (comp), Historia ¿para qué? Revisitas a una vieja pregunta. Los Polvorines: Ediciones UNGS.

Calveiro, P. (1998). Poder y desaparición. Buenos Aires: Colihue.

Crenzel, E. (2010). El Operativo Independencia en Tucumán. En F. Orquera (ed.), Ese ardiente Jardín de la República. Formación y desarticulación de un "campo" cultural: Tucumán, 1880-1975 (pp. 377-400). Córdoba: Alción Editora.

Comisión Bicameral de la Provincia de Tucumán (1991). Informe de la Comisión Bicameral Investigadora de las violaciones a los Derechos Humanos en la Provincia de Tucumán. San Miguel de Tucumán: EDUNT.

CONADEP (1985). Nunca más. Informe de la Comisión Nacional sobre la desaparición de personas. Buenos Aires: EUDEBA.

Da Matta, R. (1999). El oficio de etnólogo o cómo tener “Anthropological Blues”. En Constructores de otredad (pp. 172-178). Buenos Aires: EUDEBA.

Feierstein, D. (2012). Interpretaciones jurídicas y sociológicas con respecto al genocidio en Argentina. Revista Nuevo Derecho Penaly Criminología, año 2, 2, 57-68.

Filipini, L. (2011). La persecución penal en la búsqueda de justicia. En Hacer justicia. Nuevos debates sobre el juzgamiento de crímenes de lesa humanidad en Argentina (pp. 19-47).Buenos Aires: Siglo XXI.

Geertz, C. (1994). Desde el punto de vista del nativo: sobre la naturaleza del conocimiento antropológico. En Conocimiento local (pp. 73-90). Barcelona: Paidós..

Guber, R. (2001). La etnografía. Método, campo y reflexividad. Buenos Aires: Norma.

Mercado, L. (2005). Santa Lucía de Tucumán. La Base. Buenos Aires: Edición de la autora.

Sarrabayrouse Oliveira, M. J. (2009). Reflexiones metodológicas en torno al trabajo de campo antropológico en el terreno de la historia reciente. Cuadernos de Antropología Social, 29, 61-83.

Taussig, M. (2006). Culture of terror - Space of death. En N. Scheper-Hughes, \& P. Bourgois (eds), Violence in War and Peace (pp. 39-53). Singapur: Blackwell.

Tiscornia, S. (2011). El trabajo antropológico, nuevas aldeas y nuevos linajes. En AAVV (orgs.), Burocracias, Direitos e Conflitos: pesquisas comparadas em Antropologia do Direito (pp. 15-23). Rio de Janeiro: Editora Garamond. 
Varsky, C. (2011). El testimonio como prueba en procesos penales por delitos de lesa humanidad. En Hacer justicia. Nuevos debates sobre el juzgamiento de crímenes de lesa humanidad en Argentina. Buenos Aires: Siglo XXI.

Vilas, A. (1977). Tucumán: el hecho histórico. El plan táctico que posibilitó la victoria contra el Ejército Revolucionario del Pueblo (ERP) en 1975. Buenos Aires: Mimeo.

Vitar, J. (2014). No hubo guerra, hubo genocidio. Familiares de desaparecidos de Tucumán y las políticas de juzgamiento a las violaciones a los derechos humanos (Tucumán 2003-2010) (Tesis de maestría), UNSAM, Buenos Aires, Argentina, mimeo.

\section{Notas}

1 Utilizaré comillas para los conceptos que provienen del mundo jurídico y del proceso penal.

2 Sobre este tópico, el "Colectivo de Historia Reciente" ha publicado dos potentes manifiestos denunciando estos retrocesos: el primero titulado "La democracia se construye con verdad y con justicia", de septiembre de 2016 (http://ww w.ungs.edu.ar/ms_ungs/index.php/la-verdadera-democracia-se-construye-con-verdad-y-con-justicia); y, el segundo, de marzo de 2017, "Frente a la banalización del terrorismo de Estado y los derechos humanos" (https://docs.google.com/ forms/d/e/1FAIpQLSeAr5d6o6gQBWUyeUg7aBvEq6ph-lskIEEawvwXRaXms2NmGg/viewform?c=0\&w=1).

3 La causa "Vargas Aignasse" fue el primer juicio oral y público en el que Bussi fue sentado en el banquillo de los acusados (lo que a su vez impidió que asumiera el cargo como intendente de la ciudad electo) y en el que fue condenado a cadena perpetua en agosto de 2008 por el secuestro y asesinato de un senador provincial peronista (ocurrido en abril de 1976). Luego, al privilegiarse el criterio alentado por FADETUC de crear "megacausas" que agruparan distintos casos de víctimas que habían sido vistas en un mismo centro clandestino de detención, desde 2008 la Justicia Federal de Tucumán elevó a juicio oral y público las siguientes investigaciones: "Jefatura de Policía I" (2010); “Arsenales I" (2010); "Jefatura II / Arsenales II" (2013) y "Villa Urquiza” (2014) (Vitar, 2014). También se elevaron otras causa que agruparon menos casos, tales como: "Romero Nikilson” y "Aguirre-Weiss" (2011); "Emma del Valle Aguirre” (2012), "Toledo de Ygel” (2013); “De Benedetti” y “Cantos” (2014); y en 2015 se condenó al exjuez Manlio Martínez. A diferencia de las anteriores "megacausas”, el decimosegundo juicio que se desarrolla en la provincia no se ha organizado en función de un centro clandestino de detención sino por un período de tiempo (se investigan los crímenes cometidos con anterioridad al golpe de Estado del 24 de marzo de 1975). Ver: http://diariodeljuiciotucuman.blogspot.com.ar.

4 Según Vitar, desde 2004, esa organización dio un impulso a las investigaciones sobre los delitos cometidos con anterioridad al golpe del 24 de marzo de 1976, aunque recién en 2012 la causa consiguió tener un avance procesal importante, con el procesamiento de cuarenta personas. Para ello, se prepararon dos "megacausas" que agrupaban a las víctimas del Operativo en dos grupos: la primera se refiere a lo sucedido durante la comandancia de Acdel Vilas, entre enero y diciembre de 1975, y los primeros meses de la de Antonio Domingo Bussi, hasta el 24 de marzo, y la segunda, con los hechos posteriores a la interrupción del orden constitucional. Sobre el Proceso de Memoria, Verdad y Justicia tucumano, véase: Vitar 2012.

5 Como dice Guber, "adoptar un enfoque etnográfico, es elaborar una representación coherente de lo que piensan y dicen los nativos, en la que esa 'descripción' no es ni el mundo de los nativos, ni como es para ellos, sino una conclusión interpretativa que elabora el investigador” (2001, p. 15). Es decir, que el desafío es producir una interpretación de la experiencia de un grupo social que no sea prisionera de sus horizontes mentales (como sería una etnografía de la brujería escrita por una bruja), ni se mantenga ajena a las tonalidades distintivas de sus existencias (como sería una etnografía de la brujería escrita por una geómetra) (Geertz, 1994, p. 75).

6 Ello así porque, según las normas procesales, a diferencia de las prestadas en la fase de instrucción, o etapa de investigación, en el juicio oral se produce la declaración valedera a los efectos probatorios (Varsky, 2011, p. 53).

7 Se trata de un sistema que permite comunicar, en este caso, el Consejo de la Magistratura, los penales de Marcos Paz, Ezeiza, Unidad N³1 del SPF, el Hospital Penitenciario 1, el Tribunal Oral Nro. 14, donde estaba el “cuarto" juez, Dr. Cataldi, y los tribunales federales ubicados en la avenida Comodoro Py, en la ciudad de Buenos Aires.

8 La reconstrucción de mi declaración fue realizada con base en mis propios apuntes y en la grabación íntegra de la audiencia, a la que accedí gracias a la gentileza de uno de los abogados querellantes. Si bien fue transcripta en forma completa, preferí optar por glosarla y sintetizarla. Aclaro que, aunque no siempre se usan comillas, se retoman fielmente los argumentos y los conceptos vertidos oralmente.

9 Revista Gente, segunda quincena de noviembre de 1975, pp. 6 y 7.

10 Véase un análisis de dicho manuscrito en Crenzel, 2010.

11 Tomado de: http://www.cij.gov.ar/nota-27673-Lesa-humanidad--condenaron-a-diez-acusados-en-el-juicio-oral-por-e 1--Operativo-Independencia-.html 
Sociohistórica, $\mathrm{n}^{\circ}$ 41, e050, 1er. Semestre de 2018. ISSN 1852-1606

12 Véase el comunicado de prensa en: http://diariodeljuiciotucuman.blogspot.com.ar/. 